\title{
The Relationship Between Flower and Fruit Abscission and Alternate Bearing of 'Hass' Avocado
}

\author{
Lauren C. Garner ${ }^{1,2}$ and Carol J. Lovatt \\ Department of Botany and Plant Sciences, University of California, Riverside, CA 92521-0124
}

\begin{abstract}
AdDitional InDEX words. fruit development, fruit set, fruit size, June drop, Persea americana, phenology, preharvest drop
Abstract. Despite profuse flowering, 'Hass' avocado (Persea americana Mill.) yields are low because of excessive flower and fruit abscission. Whether the dynamics of flower and fruit abscission are influenced by or contribute to alternate bearing, the production of a heavy on-crop followed by a light off-crop that is characteristic of many avocado cultivars, remains unresolved. The objective of this research was to determine whether abscission of reproductive structures from 'Hass' avocado trees during specific developmental stages, including flowering, fruit development, and fruit maturity, was influenced by crop status of the current or preceding year. Abscised reproductive structures were collected from commercially bearing trees during two complete crop years. Flower abscission began at about the same time but peaked 1 month later in the off-crop year compared with the on-crop year. Peak abscission rates were lower during the off-crop year than the on-crop year (compare $1836 \pm 403$ to $5378 \pm$ 856 flowers per day and $50 \pm 18$ to $280 \pm 23$ immature fruit per day, respectively). The off- or on-crop status of the tree did not influence the percentage fruit set, average fruit diameter, or biomass of individual fruit that abscised at similar phenological stages. Furthermore, flower and fruit abscission were not influenced by the number of mature fruit from the previous year's crop. In both years of the research, as immature fruit abscission declined, abscission of the preceding year's crop increased, indicating that the processes were controlled independently. During the study, neither weather conditions nor tree nutrient status were associated with key abscission events. Taken together, these results provide evidence that the previous year's yield does not influence flower or fruit abscission and the seasonal abscission of reproductive structures is an independent process that does not contribute to alternate bearing of 'Hass' avocado.
\end{abstract}

Despite a theoretical capacity of $32.5 \mathrm{t} \cdot \mathrm{ha}^{-1}$ of fruit with $17 \%$ oil content (Wolstenholme, 1986), the 10-year worldwide average avocado yield from 1993 to 2002 was only 8.7 t.ha ${ }^{-1}$ (Avocadosource.com, 2003). Studies have demonstrated that increased flower and fruit abscission can occur as a result of numerous factors, including temperature extremes, nutritional deficiencies, and genetic factors. Even with optimal conditions, avocado flower and fruit abscission is still excessive. Avocado trees are physiologically capable of bearing larger crops.

Low yields are not the result of poor flowering. The avocado flowers profusely. For example, researchers in California found an average of 113 flowers per inflorescence (Salazar-García and Lovatt, 1998) and two to 13 floral shoots per 1-m branch every year (Salazar-García et al., 1998). In the few studies designed to quantify flower abscission on a whole-tree basis, researchers found that individual avocado trees can lose tens of thousands (Inoue and Takahashi, 1990) or even hundreds of thousands (Cameron et al., 1952; Lahav and Zamet, 1975; Slabbert, 1981) of flowers in a single season. In addition to significant flower loss, many avocado cultivars are also characterized by high rates of immature fruit abscission (Davenport, 1982; Inoue and

Received for publication 26 Aug. 2005. Accepted for publication 6 Oct. 2007. This research was supported in part by the Citrus Research Center and Agricultural Experiment Station of the Univ. of California, Riverside.

This paper represents a portion of the dissertation submitted by L.C.G. in partial fulfillment of requirements for a Ph.D. in Botany at the Univ. of California, Riverside. L.C.G. acknowledges the support of the Univ. of California Riverside.

We thank Rick Shade of Shade Farm Management (Carpinteria, CA) for use of the orchard and assistance with harvests.

${ }^{1}$ Current address: Horticulture and Crop Science Department, CA Polytechnic State University, San Luis Obispo, CA 93407.

${ }^{2}$ Corresponding author. E-mail: lgarner@calpoly.edu.
Takahashi, 1990; Lahav and Zamet, 1975; Slabbert, 1981) where thousands of fruit have been reported to abscise per tree in a single season (Lahav and Zamet, 1975; Slabbert, 1981). Researchers report that most fruit abscission occurs within a few months of the end of bloom, with high rates of fruit abscission in the spring and summer followed by gradually declining rates of fruit abscission and negligible abscission through the fall as developing fruit approached maturity (Adato and Gazit, 1977; Lahav and Zamet, 1975; Perez et al., 1988). Final wholetree fruit set ranges from a low of $0.001 \%$ for 'Bacon' trees in Japan (Inoue and Takahashi, 1990) to a high of $0.07 \%$ for California 'Fuerte' trees (Cameron et al., 1952), though the intensity, timing, and longevity of the abscission periods varies with cultivar and location. Taken together, these studies indicate that avocado flower and fruit abscission are excessive. Clearly, a strategy to reduce the abscission of reproductive structures would increase avocado yield.

The reproductive phenology of many avocado cultivars, including 'Hass', is further characterized by alternate bearing. Alternate bearing is a seasonal cycle of heavy "on" and light "off" crops, triggered initially by conditions that result in extremely low or high flower production, fruit set, or yield (reviewed in Monselise and Goldschmidt, 1982). Alternate bearing becomes entrained because of the effect of one year's crop on the subsequent year's bloom. Although the relationship between mature avocado fruit and the initiation of vegetative and floral shoots has been investigated (Davenport, 1982; Salazar-García et al., 1998), the effects of alternating on- and off-crops on flower and fruit abscission are poorly characterized. The postponement of avocado harvests until bloom and early fruit set of the following year can trigger alternate bearing (Whiley et al., 1996a, 1996b), suggesting that an on- or off-crop might affect flower and fruit abscission differently. Early 
harvests did not stabilize yields of orchards already alternate bearing (Whiley et al., 1996a). Monselise and Goldschmidt (1982) state that on-year crops limit resources, possibly increasing fruit abscission rates of a developing crop. A causal relationship between resource availability and fruit abscission has not been demonstrated for avocado.

Low yield of the avocado is the result of a series of abscission events that occur throughout reproductive development. Determination of abscission-sensitive stages during reproductive development is prerequisite to research into the physiological basis underlying this low yield and the development of agricultural strategies to increase yield and grower profit by retention of reproductive structures. Furthermore, resolution of the role that the off- and on-crop status of the trees plays in flower and fruit abscission is key to developing strategies to mitigate alternate bearing of 'Hass' avocado. Therefore, this study was conducted to identify abscissionsensitive stage(s) of 'Hass' avocado reproductive development and to quantify the impact of the off- and on-crop status of the trees on these abscission events.

\section{Materials and Methods}

Field CONDitions. Ten commercially bearing 6-year-old 'Hass' avocado trees on Mexican race rootstocks in an orchard in Carpinteria, California (lat. $34^{\circ} 23^{\prime} \mathrm{N}$, long. $119^{\circ} 29^{\prime} \mathrm{W}$ ) were selected for uniform health, size, and vigor. A net $\left(37.2 \mathrm{~m}^{2}\right.$ from $73 \%$ black shade cloth) was installed under each data tree. The net area exceeded the canopy area, allowing for the capture of all abscised structures. Furthermore, neighboring trees did not have branches that extended into the canopy of data trees. Data trees were subject to the same standard cultural practices as the remaining orchard trees, including limited winter top and side pruning. Throughout the study period, irrigation scheduling was based on evaluation by the hand-feel method of soil samples collected from the root zone at a depth of $61 \mathrm{~cm}$. Estimated soil moisture deficit did not exceed 50\% throughout the study. Honeybees were active in the orchard during each bloom period.

SAMPle Collection, Processing, AND ANAlysis. The experiment was initiated during bloom and continued for three consecutive 18-month crop years until the final harvest. On each collection date, trees were shaken gently to dislodge all abscised flowers and fruit from the canopy into nets. Preliminary experiments demonstrated that this procedure removed abscised and abscising fruit without breaking intact pedicels. All nets were emptied with hand brooms and dustpans about weekly during major periods of flower and immature fruit abscission in spring and summer and biweekly thereafter. Collections began on 27 June of Year 1 and continued until 28 Sept. of Year 3, for a total of 76 collection dates.

Samples were stored in sealed plastic bags in a refrigerator to prevent water loss before analysis. The total flower number per sample was estimated by weighing a random subsample of 50 flowers. Fruit greater than $2 \mathrm{~mm}$ in diameter was counted individually. The rates of flower and fruit abscission were calculated by dividing the number of each organ collected by the number of days between collection dates. The equatorial diameter and mass were determined for up to 25 randomly selected fruit per sample.

In a separate experiment conducted in this orchard, random samples of five fruit picked over time met or exceeded the minimum maturity standard (21.2\% dry matter/fruit) by March of each of the two crop years. Therefore, in analyzing abscission data, fruit that abscised before March were considered immature fruit, whereas those that abscised during or after March were considered mature.

Yield was significantly higher in the first and third crop years $(67.05 \pm 7.83 \mathrm{~kg}$ per tree and $85.30 \pm 13.44 \mathrm{~kg}$ per tree, respectively) than in the second year $(12.88 \pm 3.38 \mathrm{~kg}$ per tree) and there was no significant difference in yield between the first and third year ( $\alpha=0.05$ for the family of comparisons). Thus, Years 1 and 3 were on-crop years and Year 2 was an off-crop year. Although two trees each had a low yield during one oncrop year, neither appeared to be on a different alternate bearing cycle. As collections did not begin until part way through flower and immature fruit abscission of Year 1, analysis of abscission data focused on the second and third crop years, hereafter referred to as the off-crop year and on-crop year, respectively. Patterns of flower and fruit abscission for Year 1 (data not shown) were generally consistent with that of the oncrop year reported herein.

Tree nutrient status. Twenty leaves from hardened, nonflowering, terminal spring vegetative growth were collected from all trees at a height of $1.5 \mathrm{~m}$ between $15 \mathrm{Aug}$. and $15 \mathrm{Sept}$. of each year of the study, and were washed, oven-dried to a constant mass (Embleton et al., 1973), and sent to Albion Laboratories, Inc. (Clearfield, UT) for mineral nutrient analysis. Samples ground to pass through a 40-mesh screen were combusted at $1350{ }^{\circ} \mathrm{C}$ and carbon, nitrogen, and sulfur were determined by thermal conductivity using a Leco Elemental Analyzer (CNS-200; Leco Corp., St. Joseph, MI). To determine phosphorous, potassium, $\mathrm{Mg}, \mathrm{Ca}, \mathrm{Fe}, \mathrm{Mn}, \mathrm{B}, \mathrm{Cu}$, and $\mathrm{Zn}$ concentrations, ground subsamples were ashed at $550{ }^{\circ} \mathrm{C}$, dissolved with $10 \% \mathrm{HCl}$, and analyzed using an inductively coupled plasma emission spectroscope (Accuris; Fisons Instruments, Beverly, MA). $\mathrm{NO}_{3}-\mathrm{N}$ was extracted in deionized water, reacted with cadmium, and analyzed at $410 \mathrm{~nm}$ with a HewlettPackard ultraviolet-visible spectrophotometer (model 8453; Agilent Technologies, Santa Clara, CA).

Weather Conditions. Weather data for the period of the study was downloaded from the California Irrigation Management Information System (CIMIS) website (California Department of Water Resources, 2003). Daily wind speed, precipitation, solar radiation, and maximum, minimum, and average air temperatures were obtained from the closest coastal

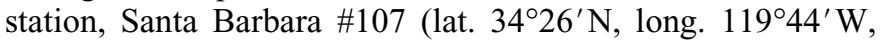
elevation $76 \mathrm{~m}$ ). CIMIS quality control criteria and comparisons with data from the National Climatic Data Center (NCDC) Santa Barbara Station [COOP ID 047902; lat. $34^{\circ} 25^{\prime} \mathrm{N}$, long. $119^{\circ} 41^{\prime} \mathrm{W}$, elevation $2 \mathrm{~m}$ (National Oceanic Atmospheric Administration, 2003)] were used to validate the data.

HARvests. At harvest in October of each year, yield (kilogram/tree) and mass of 100 randomly selected fruit were determined and used to calculate the total number of fruit per tree and pack-out (i.e., kilograms fruit of each packing carton size per tree). The following packing carton sizes (grams per fruit) were used: size 84 (99-134 g), size 70 (135-177 g), size 60 (178-212 g), size 48 (213-269 g), size 40 (270-325 g), size 36 (326-354 g), and size 32 (355-397 g).

To express the degree of alternate bearing, the alternate bearing index (ABI) was calculated for the 2 -year period using the equation: 


$$
\mathrm{ABI}=\left(\text { yield }_{\text {year1 }}-\text { yield }_{\text {year } 2}\right) /\left(\text { yield }_{\text {year } 1}+\text { yield }_{\text {year2 }}\right),
$$

in which yield was defined as total kilograms of fruit per tree. ABI ranges from 0 (no alternate bearing) to 1 (complete alternate bearing) (Pearce and Dobersek-Urbanc, 1967). All data trees were alternate bearing, with a mean ABI of $0.70 \pm$ 0.09. Furthermore, data from Year 1 confirmed that the degree of alternate bearing was similar across the three years of the study and that the off- or on-crop status of study trees was the same within a given crop year.

Statistical analyses. Mean comparisons were conducted using paired two-tailed Student's $t$ tests at $P \leq 0.05$ or analysis of variance (ANOVA) and Tukey's Studentized multiple-comparison procedure with a family error rate of $\alpha \leq$ 0.05 . With the exception of analyses of the size of abscised fruit, all regression analyses were conducted using the least squares method for the general linear model. Percentage data were normally distributed and, therefore, was not transformed before analyses. Significant linear regressions were tested to determine if outliers distorted the regression lines significantly using a method described by Neter et al. (1990). If regression analyses were not significant $(P>0.05)$ upon removal of the outlier, the relationship was described as not significant. Regressions with weather data were based on averages of daily weather data for the collection date and preceding $6 \mathrm{~d}$. The above-described analyses were conducted using Minitab (Minitab Inc., State College, PA).

Data for the size of abscised fruit were analyzed using the nonlinear least squares procedure of SAS (SAS Institute, Cary, NC). For biomass data this model was quadratic. For diameter data, the following model for fitting sigmoid data sets was used:

$y=\left(\left(\beta_{0}-\beta_{3}\right) /\left\{1+\left[\left(x / \beta_{2}\right)^{\wedge} \beta_{1}\right]\right\}\right)+\beta_{3}$,

where $\beta_{0}=$ the value of $y$ at the beginning of the curve, $\beta_{3}=$ the value of $y$ at the end of the curve, $\beta_{1}=$ the value of $\mathrm{x}$ at the point where $y$ is halfway between $\beta_{0}$ and $\beta_{3}$, and $\beta_{2}=$ the slope (Ott, 1993). To test if curves were significantly different, Bonferroni joint confidence intervals for joint estimations of regression coefficients were constructed using the method described by Neter et al., (1990).

\section{Results}

Flower ABSCision Over Time. During both crop years, flower abscission began in February and ended in July, with more than 75,000 and 339,000 flowers abscised during the offand on-crop year, respectively. The abscission rate peaked 1 month later in the off-crop year compared with the on-crop year (2 June and 4 May, respectively) and the number of flowers abscised per day was 3-fold lower in the off-crop year than in
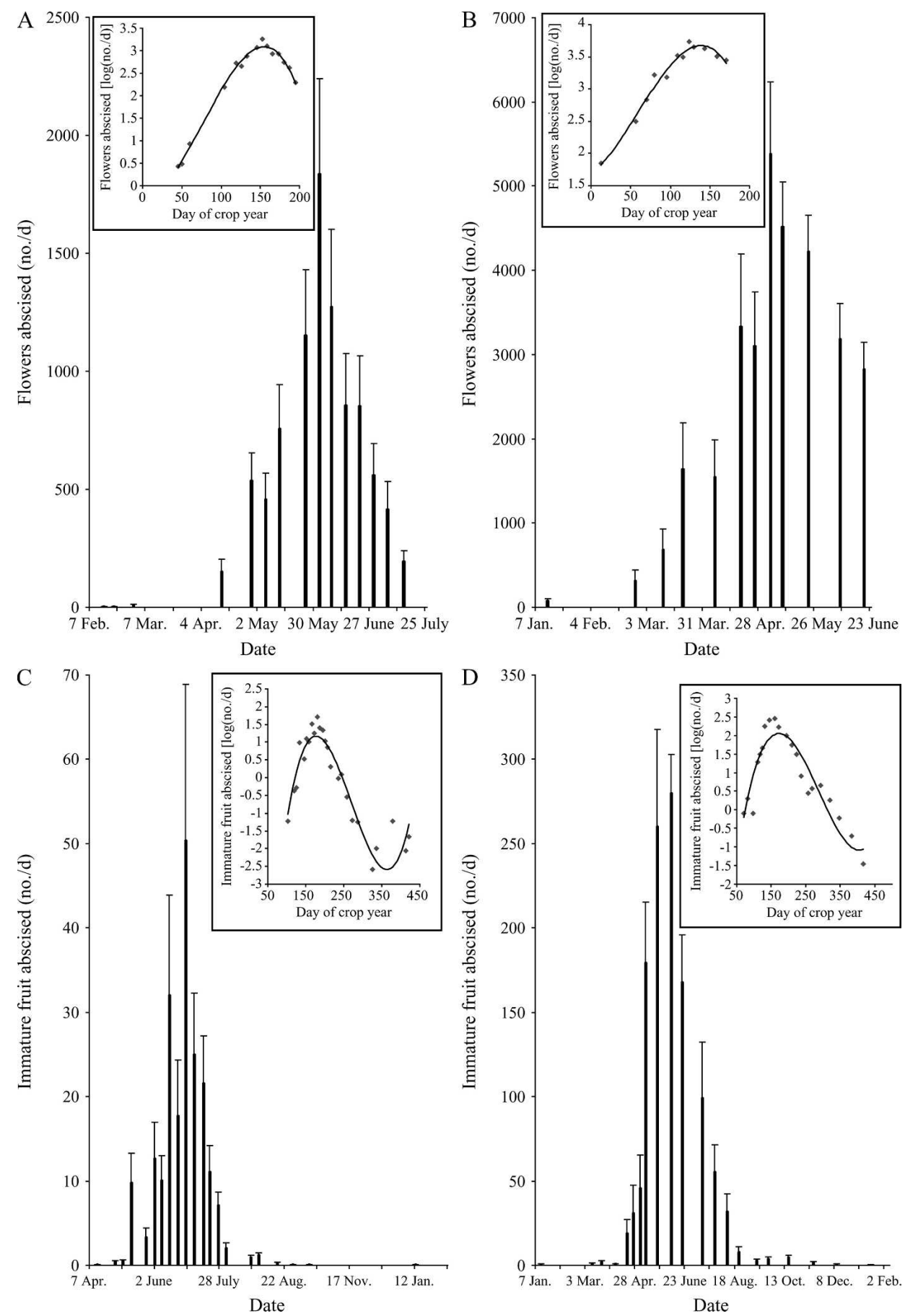

Fig. 1. Number of avocado flowers or immature fruit abscised per day during the off- or on-crop year. (A) Off-crop flower abscission, (B) on-crop flower abscission, (C) off-crop immature fruit abscission, and (D) on-crop immature fruit abscission. Error bars represent the SE for that collection period. Inset: $\log$ fruit abscission rate (no./day) versus day of the year. Day of the year: $1=1$ Jan. of crop year, $366=1$ Jan. of following year. 
the on-crop year (1836 \pm 403 and $5378 \pm 856$ flowers per day, respectively; Fig. 1A and $1 \mathrm{~B})$. The pattern of flower abscission was expressed as a cubic function of the day of the year $(P \leq$ $0.001)$ and was similar in the off- and on-crop years $\left(R^{2}=0.99\right.$ and 0.98 , respectively). Flowers comprised more than $90 \%$ of the number of reproductive organs abscised during either year and this percentage was significantly higher during the off-crop year compared with the on-crop year $(98.07 \% \pm 0.22 \%$ and $94.97 \% \pm 0.66 \%$, respectively; $P \leq 0.01)$.

FrUit ABSCISSION OVER TIME. Fruit abscission began shortly after flower abscission started each year (Fig. 1C and 1D). During both crop years, fruit abscission rates increased during spring and peaked in June $(50 \pm 18$ and $280 \pm 23$ fruit per day in the off- and on-crop years, respectively) about 1 month after peak flower abscission. Fruit abscission rates then decreased sharply, with the rate of abscission approaching zero fruit per day during the fall and early winter (Fig. 1C and 1D). Therefore, the timing of immature fruit abscission during the off- and on-crop years was similar despite differences in the magnitude of the number of fruit abscising. The log of the number of immature fruit abscised per day could be expressed as a cubic function of the day of the year $(P \leq 0.001)$, with the off- and on-crop years having curves of a similar shape and high coefficients of multiple determination $\left(R^{2}=\right.$ 0.90 and 0.88 , respectively; Fig. $1 \mathrm{C}$ and 1D). When expressed as a percentage of the total number of reproductive organs abscised, immature fruit abscission was significantly lower in the off- than in the on-crop year $(1.92 \% \pm 0.22 \%$ and $5.02 \% \pm 0.66 \%$, respectively; $P \leq 0.01)$.

Fruit maturity was reached in March, about 1 year after flowering. After this point, the rate of mature fruit abscission remained extremely low throughout the spring and summer, irrespective of crop load. Mature fruit abscission then increased sharply in the fall, reaching a maximum during September, with 16 and 25 fruit per tree abscising per month for the off- and on-crop trees, respectively. Neither the number nor percentage of mature fruit abscised was significantly different between crop years $(P=0.05)$.

Despite crop-year differences in number of fruit abscised per day (Fig. 2, left-hand y-axes) and yield, the average biomass of individual fruit that abscised (Fig. 2, righthand $\mathrm{y}$-axes) was consistent $(\leq 3 \mathrm{~g})$ from bloom through fruit set and then began to increase measurably until harvest of the off- and on-crop. There was a significant quadratic relationship between the biomass of abscised fruit and day of the year for both crop years (Fig. 2, right-hand $y$-axes), and the coefficients of these two equations were not significantly different from one another $(\alpha=0.05$ for the family of comparisons). Plotting abscised fruit diameter versus day of year resulted in sigmoid curves (Fig. 3) that were not statistically significantly different between off- and on-crop years ( $\alpha=0.05$ for the family of comparisons). Furthermore, diameters of abscised fruit from the final collection date before harvest of each crop year were not significantly different $(P=0.05)$.
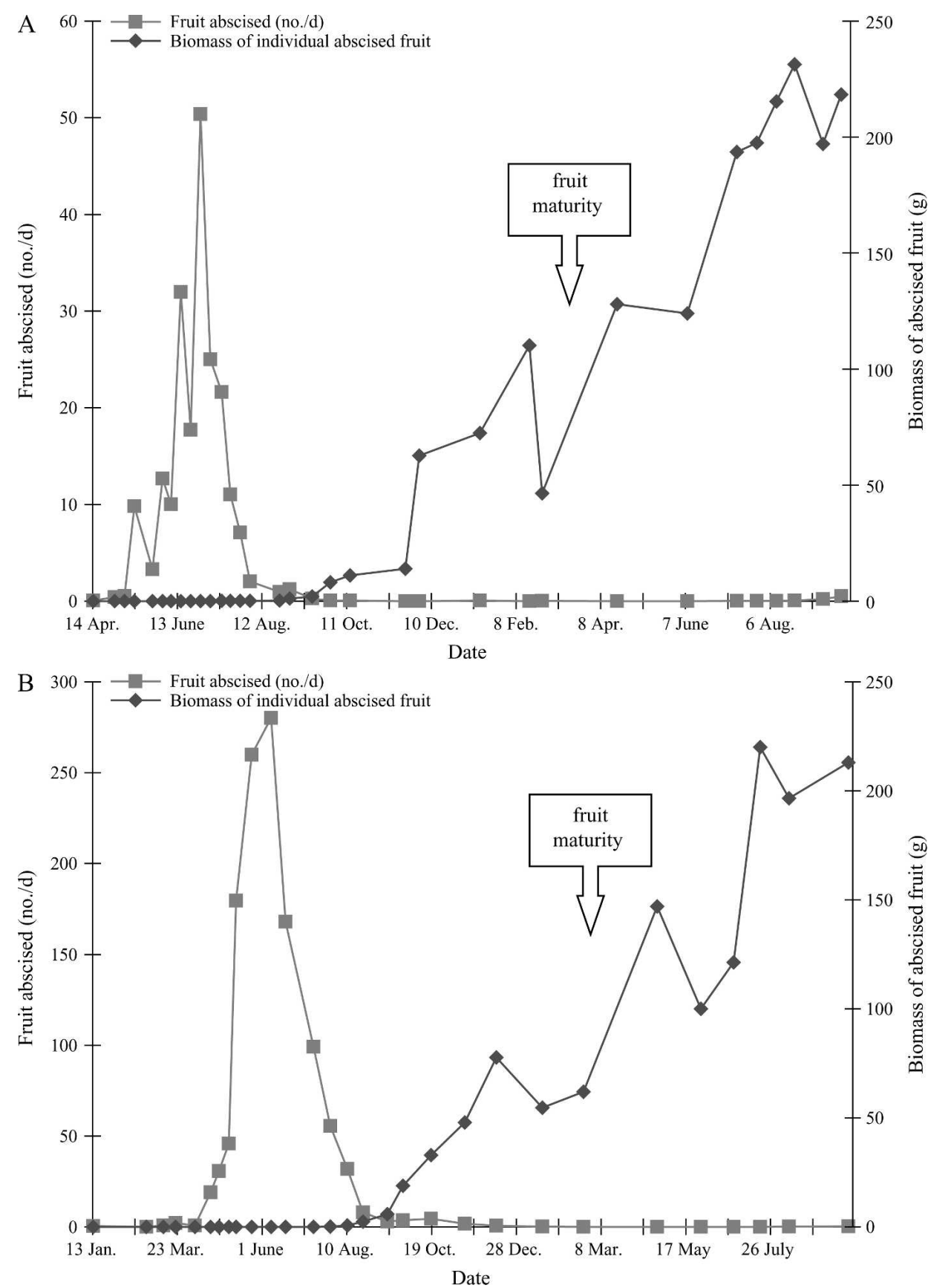

Fig. 2. The relationship between the number of avocado fruit abscised per day and the biomass of individual abscised fruit during (A) the off-crop year and (B) the on-crop year. 

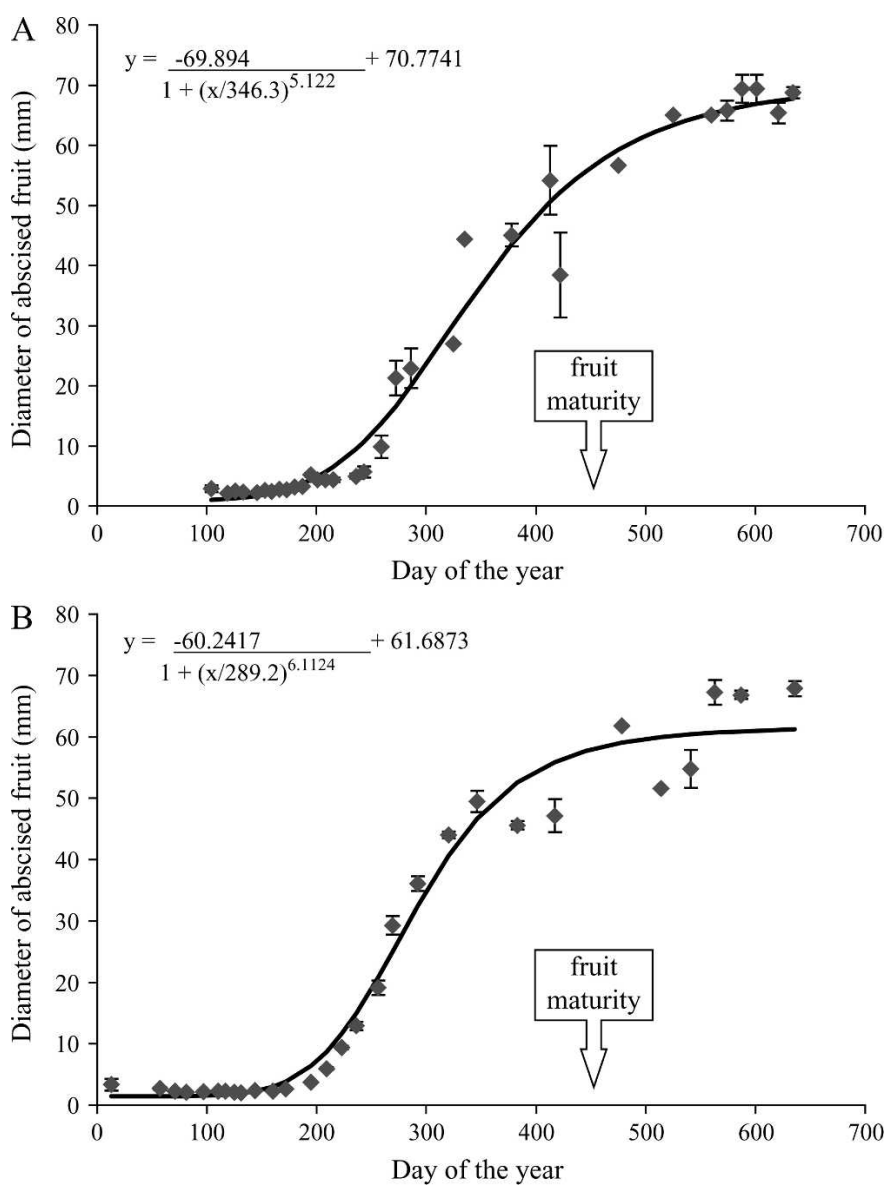

Fig. 3. The diameter of individual abscised avocado fruit during (A) the off- and (B) on-crop years. Error bars represent the SE for that collection period. Day of the year: $1=1$ Jan. of crop year, $366=1$ Jan. of following year.

EFFect OF ALTERNATE bEARING ON FRUIT SET AND SIZE. Percentage fruit set per tree was calculated by dividing the number of fruit harvested by the total number of potential fruiting points, which was estimated by adding the number of abscised flowers and fruit collected to the number of fruit harvested. Percentage fruit set in the off- and on-crop years $(0.07 \% \pm 0.02 \%$ and $0.14 \% \pm 0.03 \%$, respectively) was not significantly different $(P=0.05)$. Though fewer fruit were harvested in the off-crop year, there was a $5 \%$ net increase in fruit of the commercially desirable large size of 178 to $325 \mathrm{~g}$ (packing carton sizes 60 to 40) in the off-crop year compared with the on-crop year $(P \leq 0.05)$.

RELATIONSHIP OF FLOWER AND FRUIT ABSCISSION TO WEATHER CONDITIONS. Daily air temperatures and solar radiation did not differ significantly between the off- and on-crop years during flower and immature fruit abscission periods $(P=0.05$; Table 1). During mature fruit abscission, lower rates of solar radiation were observed during the on-crop year than for the off-crop year $(P \leq 0.001$; Table 1$)$. Significant relationships between daily maximum or minimum air temperatures or levels of solar radiation and number of abscised fruit were not detected by regression analysis for either crop year $(P=0.05)$.

Wind speed and precipitation data were collected to investigate the possible effects of weather-induced mechanical stress on fruit abscission. The wind never reached a speed greater than $3.7 \mathrm{~m} \cdot \mathrm{s}^{-1}$, which is defined as a "gentle breeze" by the Beaufort scale of wind speed (Rowlett, 2001). This wind speed is unlikely to generate the force required to remove flowers or fruit with intact abscission zones from a tree. Thus, statistical relationships between wind speed and abscission rates were not investigated. There were few incidences of overlap between precipitation and major periods of flower and fruit abscission. The one instance of substantial rain that occurred concurrently with flower and immature fruit abscission (118 mm on $17 \mathrm{Apr}$. of the on-crop year) was not associated with a detectable spike in abscission. Precipitation data were not used to make inferences about the relationship between water status and water availability with flower and fruit abscission because the orchard was irrigated as required with respect to soil moisture content, thereby preventing water deficit stress during flower and immature fruit abscission throughout the study.

RELATIONSHIP OF FLOWER AND FRUIT ABSCISSION TO LEAF NUTRIENT STATUS. There were no significant relationships between measured leaf nutrient concentrations and the number of flowers, immature fruit, mature fruit, or total number of reproductive structures that abscised $(P=0.05)$.

RELATIONSHIP OF FLOWER AND FRUIT ABSCISSION TO FINAL YIELD. To investigate possible relationships between yield and flower and fruit abscission, linear regressions were conducted between the number of flowers, immature fruit, mature fruit, or total reproductive structures abscised and harvested fruit number (Table 2) for the off- and on-crop years and for the 2-year cumulative yield. Regressions between the number of abscised organs and yield differed between the off- and on-crop years in terms of significance and direction of the slope. During the off-crop year, significant positive correlations were detected between the number of flowers, mature fruit, or total reproductive structures abscised and the number of fruit harvested that crop year. During the on-crop year, the number of abscised mature fruit was significantly, negatively correlated with fruit biomass at harvest. Cumulative data for the two crop years resulted in no significant correlations between abscised and harvested fruit number. Regression results between biomass of

Table 1. Daily air temperatures and solar radiation $( \pm \mathrm{SE})$ recorded during avocado flower, immature fruit, and mature fruit abscission of the off- and on-crop years.

\begin{tabular}{|c|c|c|c|c|c|c|c|c|c|}
\hline & \multicolumn{3}{|c|}{ Flower abscission } & \multicolumn{3}{|c|}{ Immature fruit abscission } & \multicolumn{3}{|c|}{ Mature fruit abscission } \\
\hline & $\begin{array}{l}\text { Off-crop } \\
\text { year }\end{array}$ & $\begin{array}{l}\text { On-crop } \\
\text { year }\end{array}$ & $t$ tests & $\begin{array}{l}\text { Off-crop } \\
\text { year }\end{array}$ & $\begin{array}{l}\text { On-crop } \\
\text { year }\end{array}$ & $t$ tests & $\begin{array}{c}\text { Off-crop } \\
\text { year }\end{array}$ & $\begin{array}{l}\text { On-crop } \\
\text { year }\end{array}$ & $t$ tests \\
\hline $\begin{array}{l}\text { Maximum } \\
\text { temperature }\left({ }^{\circ} \mathrm{C}\right)\end{array}$ & $19.2 \pm 0.3$ & $19.7 \pm 0.3$ & NS & $21.0 \pm 0.2$ & $20.4 \pm 0.2$ & NS & $22.4 \pm 0.2$ & $21.3 \pm 0.2$ & $* *$ \\
\hline $\begin{array}{l}\text { Minimum } \\
\text { temperature }\left({ }^{\circ} \mathrm{C}\right)\end{array}$ & $9.7 \pm 0.2$ & $10.1 \pm 0.2$ & NS & $10.8 \pm 0.2$ & $10.4 \pm 0.2$ & NS & $12.5 \pm 0.2$ & $12.5 \pm 0.2$ & NS \\
\hline $\begin{array}{l}\text { Solar } \\
\quad \text { radiation }\left(\mathrm{W} \cdot \mathrm{m}^{-2}\right)\end{array}$ & $260 \pm 6$ & $258 \pm 8$ & NS & $214 \pm 5$ & $209 \pm 5$ & NS & $273 \pm 5$ & $245 \pm 6$ & $* * *$ \\
\hline
\end{tabular}

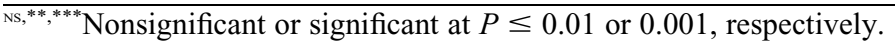


abscised organs and yield (kilogram/tree) were the same as those for number of abscised reproductive structures.

RELATIONSHIP BETWEEN THE PRECEDING YEAR'S CROP AND THE CURRENT BLOOM. Abscission of flowers and immature fruit of the current year occurred as mature fruit from the preceding crop year continued to develop on the trees. Therefore, regression analyses were conducted between number of organs abscised and yield of the preceding year. When the previous year's crop was an "on" crop, there was a weak but significant negative correlation between the "on" yield and the flower abscission rate of the current "off" bloom, whereas the correlation between the preceding crop year's "off" yield and flower abscission rate of the current on-crop was positive (Table 3 ).

Regression analyses indicated that there were no significant relationships between the number of abscised flowers and immature fruit and the number of abscised mature fruit of the preceding year's crop (data not shown). However, immature fruit abscission declined during the off- and on-crop years at the time that abscission of mature fruit of the preceding year's crop increased (Fig. 4).

\section{Discussion}

Flower and fruit abscission of flowering tree species are often characterized as occurring during flower drop, early fruit drop, "June" drop, and "pre-harvest" drop; the results of this study indicate that 'Hass' avocado fits this model of distinct periods of abscission. The timing of abscission in this study was generally consistent with that observed among other cultivars and in other countries, with heavy flower and fruit abscission occurring during the spring and summer (Davenport, 1982; Demirkol, 2002; Falcão et al., 2001; Kaiser and Wolstenholme, 1993; Levin, 1981; Robinson et al., 2002; Scholefield et al., 1985).

Table 2. The significance of linear regressions between the number of avocado reproductive structures abscised each crop year and the final number of fruit harvested.

\begin{tabular}{lccccccc}
\hline & \multicolumn{3}{c}{ Off-crop year } & & \multicolumn{3}{c}{ On-crop year } \\
\cline { 2 - 4 } \cline { 6 - 8 } Structure abscised & $P$ & $r^{2}$ & Slope $^{\mathrm{z}}$ & & $P$ & $r^{2}$ & Slope \\
\hline Flowers & $* * *$ & 0.74 & + & $\mathrm{NS}$ & & \\
Immature fruit & $\mathrm{NS}$ & & & $\mathrm{NS}$ & & \\
Mature fruit & $* *$ & 0.70 & + & $* *$ & 0.67 & - \\
$\quad \begin{array}{l}\text { Total flowers } \\
\quad \text { and fruit }\end{array}$ & $* * *$ & 0.74 & + & NS & & \\
\hline
\end{tabular}

${ }^{z_{+},-}$represents a positive or negative slope, respectively.

Ns,,$* * * * * *$ Nonsignificant or significant at $P \leq 0.01$ or 0.001 , respectively.

Table 3. The significance of linear regressions between the preceding year's on or off avocado yield and the number of reproductive structures abscised during the current crop year.

\begin{tabular}{|c|c|c|c|c|c|c|}
\hline \multirow{3}{*}{$\begin{array}{l}\text { Subsequent year's } \\
\text { abscised structure } \\
\text { (no./tree) }\end{array}$} & \multicolumn{6}{|c|}{ Preceding year's yield (no./tree) } \\
\hline & \multicolumn{3}{|c|}{ On-crop } & \multicolumn{3}{|c|}{ Off-crop } \\
\hline & $P$ & $r^{2}$ & Slope $^{z}$ & $P$ & $r^{2}$ & Slope \\
\hline Flowers & $*$ & 0.43 & - & $*$ & 0.57 & + \\
\hline Immature fruit & $*$ & 0.41 & - & NS & & \\
\hline $\begin{array}{c}\text { Total flowers } \\
\text { and fruit }\end{array}$ & $*$ & 0.43 & - & $*$ & 0.57 & + \\
\hline
\end{tabular}

${ }^{z_{+},-}$represents positive or negative slope, respectively.

${ }_{\text {Ns, }}{ }^{*}$ Nonsignificant or significant at $P \leq 0.05$, respectively.
The severity of alternate bearing was consistent with that of the California avocado industry (Lovatt, 2003). Mathematical relationships between flower or immature fruit abscission and the day of year were similar during off- and on-crop years, despite differences in the number and total mass of reproductive structures abscised. Key stages or periods in the phenology of reproductive structure abscission were identified and typically occurred independent of the off- or on-crop status of the trees. Flower abscission began immediately after the start of flower opening (February) and peaked at about the same time as full bloom (June and May of the off- and on-crop years, respectively). Interestingly, immature fruit abscission also began shortly after flowering and peaked $\approx 1$ month after bloom abscission peaked. Other studies have demonstrated that most avocado fruit abscise within a few months of the end of the bloom, followed by a gradually declining rate of fruit abscission, with fruit abscission ceasing in October (Adato and Gazit, 1977; Perez et al., 1988). In the study reported herein, substantial fruit abscission continued for several months after flower abscission ended, continuing until September of both crop years. The off- or on-crop status of the trees did not have a significant effect on the size of fruit abscised at a given time of the crop year, suggesting that fruit abscission was the result of physiological or genetic factors independent of crop load. Regardless of the off- or on-crop status of the trees, fruit reached maturity in March, $\approx 1$ year after bloom began, but abscission of mature fruit did not begin until the fall.

Not surprisingly, the significantly larger number of flowers produced during the on-bloom resulted in higher rates of flower and immature fruit abscission during the on-crop year than the off-crop year. Although increasing pollination and fertilization rates might decrease flower abscission rates, a sizeable number of immature fruit abscised after early fruit abscission of the offand on-crop years, suggesting that June drop might be the most critical and efficient time to target 'Hass' avocado with strategies designed to increase final fruit set. In contrast, the number of mature fruit abscised did not vary with alternate bearing, suggesting that different mechanisms are responsible for abscission of immature versus mature fruit. Other researchers have reported large seasonal losses with tens to hundreds of thousands of flowers and hundreds to tens of thousands of fruit abscised (Cameron et al., 1952; Inoue and Takahashi, 1990; Lahav and Zamet, 1975; Slabbert, 1981). The present research is one of the few studies to specifically measure mature avocado fruit abscission. One study that examined abscission of mature fruit reported that it did not occur in monitored fruit samples (Adato and Gazit, 1977).

That immature fruit abscission declined at the same time that abscission of mature fruit of the preceding year's crop began to increase suggests that the cause of abscission differed with fruit maturity. Regression analyses between the abscission of flowers and fruit and the yield of the preceding year's crop were weak or insignificant. Similar results were found by Lahav and Zamet (1975). Also, there were no significant relationships between the biomass or number of abscised flowers and immature fruit and the biomass or number of abscised mature fruit of the preceding year's crop. These findings indicate that abscission of immature and mature fruit were independently controlled and were not simply the result of an undiscriminating abscission factor, competition for resources, or alternate bearing. Furthermore, immature fruit might actively export a substance that ultimately results in mature fruit abscission. 

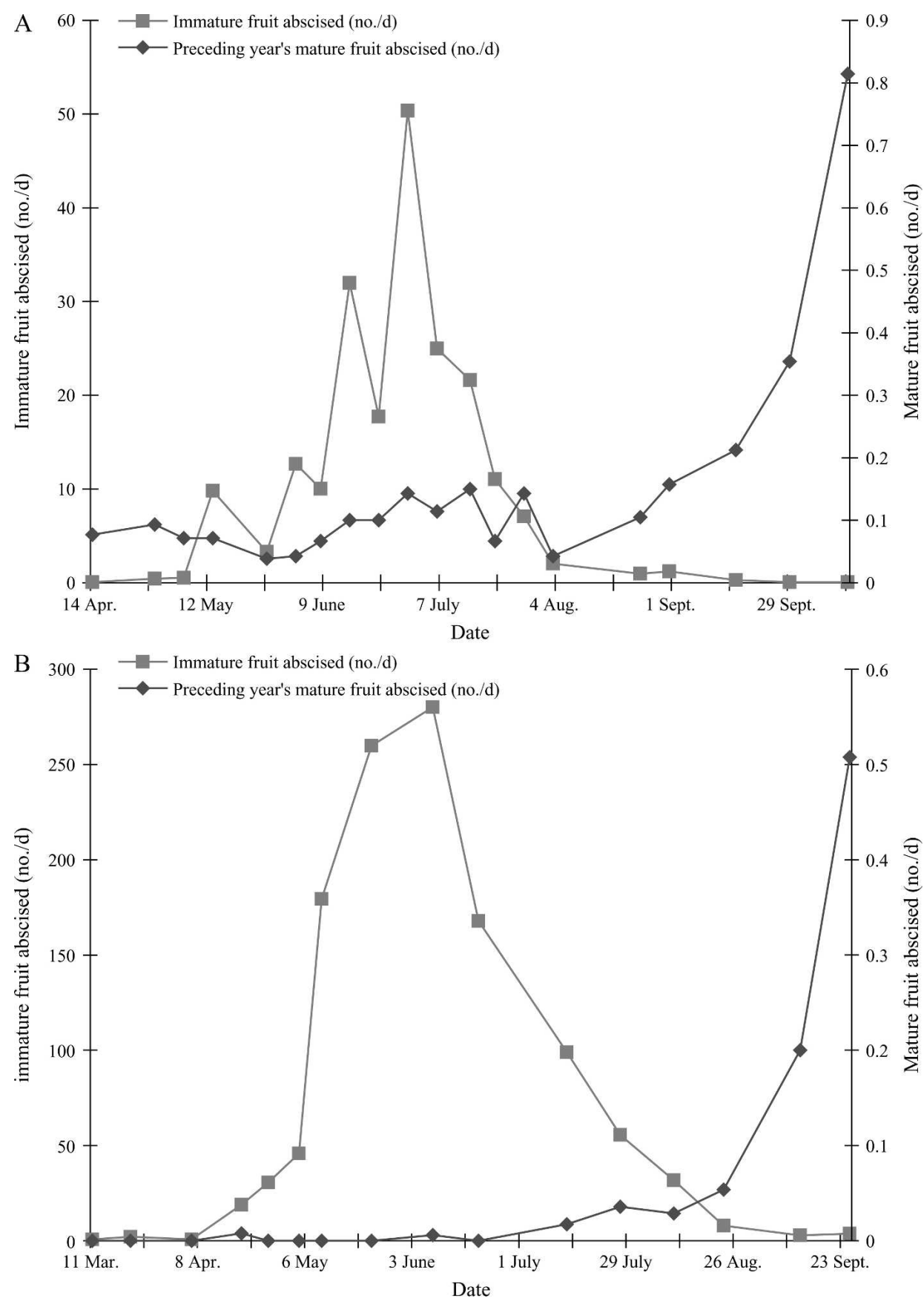

Fig. 4. The relationship between immature avocado fruit abscission and abscission of mature fruit of the preceding year's crop during $(\mathbf{A})$ the off-crop year and $(\mathbf{B})$ the on-crop year.

Such a mechanism would decrease resource competition for the developing crop and increase dispersal of late-hanging mature fruit.

Previous research has demonstrated that environmental conditions can affect flower and fruit abscission. Although minimum air temperatures during flowering were low enough $\left(<12{ }^{\circ} \mathrm{C}\right)$ to inhibit pollen tube growth (Sedgley, 1977; Sedgley and Annells, 1981) and ovule viability (Sedgley and Annells, 1981), they were consistently so, and were not associated with significant changes in flower drop during either year. A daily maximum air temperature greater than $33{ }^{\circ} \mathrm{C}$ is required to cause heat stress sufficient to result in fruit abscission (Lomas,
1988). This air temperature was not reached during the course of this research. Furthermore, severe wind and precipitation events and water stress were not observed during the study period. Therefore, environmental conditions were relatively consistent during the 3 years of this research and likely never reached the extremes necessary to influence the pattern of flower and immature fruit abscission.

There were no significant relationships between leaf nutrient concentrations and the number of abscised flowers and fruit. Leaf nutrient values had low levels of variation and were typically within recommended ranges (Reuter and Robinson, 1986), and the trees were not subject to salt stress. It is unlikely that alternate bearing observed in this study was the result of nutrient deficiency. A significant relationship might exist between sub- or superoptimal nutrient concentrations and flower and fruit abscission, but these conditions were not detected during this research. Additionally, relationships between flower or fruit abscission and leaf nutrient concentrations could be spatially or temporally isolated and therefore, not detectable in August or September, the standard time in California for collecting leaves for nutrient analyses. Because environmental conditions and nutritional deficiencies previously found to be associated with abscission were not present in this orchard during the research period, the physiological effects of alternate bearing on flower and fruit abscission of 'Hass' avocado were not confounded. Thus, it was uniquely possible to determine the effect of crop status on the abscission of reproductive structures.

The percentage of flowers that produced mature harvested fruit was not significantly different between the off- and oncrop years, indicating that fruit set was dependent largely on the initial number of flowers. If yields were solely the product of resource availability, percentage fruit set would be higher during off-crop years when source competition between fruit is limited. Notably, percentage fruit set was numerically lower during off- than on-crop years, although this difference was not statistically significant. Furthermore, at any given time, abscised immature fruit were similar in size, regardless of the number of fruit developing. Regressions between the number of harvested fruit and that of abscised reproductive structures from 
the same crop year often resulted in positive significant relationships, again indicating that the more flowers on the tree, the greater the amount of material abscised per tree, but also the greater the yield. This is consistent with the idea that yield is not solely resource-limited, but is instead based on physiological processes that, within limits, control abscission regardless of the off- or on-crop status of the tree. Taken together, these results indicate that alternate bearing is neither the result of nor cause of flower or fruit abscission.

\section{Literature Cited}

Adato, I. and S. Gazit. 1977. Role of ethylene in avocado fruit development and ripening. I. Fruit drop. J. Expt. Bot. 28:636-643.

Avocadosource.com. 2003. Worldwide avocado data. 2 Dec. 2003. $<$ http://www.avocadosource.com/world.asp\#>.

California Department Water Resources. 2003. California Irrigation Management Information System. 30 June 2003. <http://www. cimis.water.ca.gov>.

Cameron, S.H., R.T. Mueller, and A. Wallace. 1952. Nutrient composition and seasonal losses of avocado trees. California Avocado Soc. Yrbk. 37:201-209.

Davenport, T.L. 1982. Avocado growth and development. Proc. Florida State Hort. Soc. 95:92-96.

Demirkol, A. 2002. Phenological and pomological characteristics and yields of some avocado cultivars grown in Antalya ecological conditions (in Turkish). Anadolu 12:49-64.

Embleton, T.W., W.W. Jones, C.K. Labanauskas, and W.J. Reuther. 1973. Leaf analysis as a diagnostic tool and guide to fertilization, p. 183-211. In: W.J. Reuther (ed.). The citrus industry, Vol. 3. University of California, Division of Agricultural Sciences, Berkeley.

Falcão, M., N.D. Paraluppi, C.R. Clement, W.E. Kerr, and M.F. Silva. 2001. Phenology and yield of avocado (Persea americana Mill.) in central Amazonia (in Portuguese). Acta Amazonica 31:3-9.

Inoue, H. and B. Takahashi. 1990. Studies on the bearing behavior and yield composition of the avocado tree (in Japanese). J. Jpn. Soc. Hort. Sci. 59:487-501.

Kaiser, C. and B.N. Wolstenholme. 1993. Aspects of late hung 'Hass' avocado (Persea americana Mill.) fruit in the Natal Midlands II. Whole tree starch cycling. South African Avocado Growers' Assn. Yrbk. 16:46-55.

Lahav, E. and D. Zamet. 1975. Flower, fruitlet and fruit abscission in avocado trees (in Hebrew). Alon Hanotea 29:556-562.

Levin, A. 1981. Factors affecting inflorescence and vegetative development regulation in avocado (Persea americana Mill.) (in Hebrew). Hebrew University of Jerusalem, Rehovot, Israel, MSc thesis.

Lomas, J. 1988. An agrometeorological model for assessing the effect of heat stress during the flowering and early fruit set on avocado yields. J. Amer. Soc. Hort. Sci. 113:172-176.

Lovatt, C.J. 2003. Eliminating alternate bearing of the 'Hass' avocado. Proc. California Avocado Res. Symp. 2003. p. 103-107.
Monselise, S.P. and E.E. Goldschmidt. 1982. Alternate bearing in fruit trees. Hort. Rev. (Amer. Soc. Hort. Sci.) 4:128-173.

National Oceanic Atmospheric Administration. 2003. National Climatic Data Center. 30 June 2003. <http://www.ncdc.noaa.gov/oa/ ncdc.html $>$.

Neter, J.W., W. Wasserman, and M.H. Kutner. 1990. Applied linear statistical models. Irwin, Homewood, IL.

Ott, R.L. 1993. An introduction to statistical methods and data analysis. Duxbury Press, Belmont, CA.

Pearce, S.C. and S. Dobersek-Urbanc. 1967. The measurements of irregularity in growth and cropping. J. Hort. Sci. 42:295-305.

Perez, R.B.M., L.S. Jankiewicz, and C. Acosta-Zamudio. 1988. Growth and abscission of avocado fruits (Persea americana Mill.) cv. Fuerte. Acta Agrobot. 41:47-59.

Reuter, D.J. and J.B. Robinson. 1986. Plant analysis: An interpretation manual. University of California, Division of Agricultural Sciences, Berkeley.

Robinson, P.W., M.V. Mickelbart, X. Liu, C. Adams, G. Witney, and M.L. Arpaia. 2002. Development of a phenological model of avocado tree growth in California. Acta Hort. 575: 859-864.

Rowlett, R. 2001. A dictionary of units of measure. 23 June 2003. $<$ http://www.unc.edu/ rowlett/units/scales/beaufort.html $>$.

Salazar-García, S., E.M. Lord, and C.J. Lovatt. 1998. Inflorescence and flower development of the 'Hass' avocado (Persea americana Mill.) during "on" and "off" crop years. J. Amer. Soc. Hort. Sci. 123:537-544.

Salazar-García, S. and C.J. Lovatt. 1998. GA 3 application alters flowering phenology of 'Hass' avocado. J. Amer. Soc. Hort. Sci. 123:791-797.

Scholefield, P.B., M. Sedgley, and D.M. Alexander. 1985. Carbohydrate cycling in relation to shoot growth, floral initiation and development and yield in the avocado. Scientia Hort. 25:99-110.

Sedgley, M. 1977. The effect of temperature on floral behaviour, pollen tube growth and fruit set in the avocado. J. Hort. Sci. 52:135141.

Sedgley, M. and C.M. Annells. 1981. Flowering and fruit-set response to temperature in the avocado cultivar 'Hass'. Scientia Hort. 14:2733.

Slabbert, M.J. 1981. Flower and fruit drop. South African Avocado Growers' Assn. Yrbk. 4:89-91.

Whiley, A.W., T.S. Rasmussen, J.B. Saranah, and B.N. Wolstenholme. 1996a. Delayed harvest effects on yield, fruit size and starch cycling in avocado (Persea americana Mill.) in subtropical environments. II. The late-maturing cv. Hass. Scientia Hort. 66:35-49.

Whiley, A.W., T.S. Rasmussen, J.B. Saranah, and B.N. Wolstenholme. 1996b. Delayed harvest effects on yield, fruit size and starch cycling in avocado (Persea americana Mill.) in two subtropical environments. I. The early-maturing cv. Fuerte. Scientia Hort. 66:23-34.

Wolstenholme, B.N. 1986. Energy costs of fruiting as a yield-limiting factor with special reference to the avocado. Acta Hort. 175:121125. 